\title{
Validation of an Integrated Airframe and Turbofan Engine Simulation for Evaluation of Propulsion Control Modes
}

\author{
Jonathan Litt* \\ NASA Glenn Research Center, Cleveland, OH 44135 \\ T. Shane Sowers ${ }^{\dagger}$ \\ Vantage Partners, LLC, Cleveland, Ohio 44135 \\ Yuan Liu \\ N\&R Engineering and Management Services, Parma Heights, Ohio 44130 \\ A. Karl Owen ${ }^{\S}$ \\ NASA Glenn Research Center, Cleveland, OH 44135 \\ and \\ Ten-Huei Guo** \\ NASA Glenn Research Center, Cleveland, OH 44135
}

The National Aeronautics and Space Administration (NASA) has developed independent airframe and engine models that have been integrated into a single real-time aircraft simulation for piloted evaluation of propulsion control algorithms. In order to have confidence in the results of these evaluations, the integrated simulation must be validated to demonstrate that its behavior is realistic and that it meets the appropriate Federal Aviation Administration (FAA) certification requirements for aircraft. The paper describes the test procedures and results, demonstrating that the integrated simulation generally meets the FAA requirements and is thus a valid testbed for evaluation of propulsion control modes.

\section{Nomenclature}

$\begin{array}{ll}\text { A } & =\text { Inlet Area } \\ \text { AEO } & =\text { All Engines Operational } \\ \text { AGL } & =\text { Above Ground Level } \\ \text { C-MAPSS40k } & =\text { Commercial Modular Aero-Propulsion System Simulation 40k } \\ C_{D, \text { wind }} & =\text { Drag Coefficient Due to Windmilling } \\ C_{L} & =\text { Coefficient of Lift } \\ \text { CFR } & =\text { Code of Federal Regulations } \\ D & =\text { Drag } \\ D_{\text {Wind }} & =\text { Drag Due to Windmilling } \\ \text { FAA } & =\text { Federal Aviation Administration } \\ \text { MCT } & =\text { Maximum Continuous Thrust } \\ \text { MSL } & =\text { Mean Sea Level, (ft) } \\ \text { NASA } & =\text { One Engine Inoperative } \\ \text { OEI } & \end{array}$

\footnotetext{
* Research Engineer, Controls and Dynamics Branch, jonathan.s.litt@nasa.gov, AIAA Senior Member

† Senior Research Engineer, tssowers@nasa.gov

* Research Engineer, yuan.liu@nasa.gov, AIAA Member.

$\S$ Distinguished Research Associate

*** Research Engineer, Controls and Dynamics Branch, ten-huei.guo-1@nasa.gov, AIAA Member.
} 


$\begin{array}{ll}q & =\text { Dynamic Pressure } \\ S & =\text { Wing Area, }\left(\mathrm{ft}^{2}\right) \\ \text { TAS } & =\text { True Air Speed } \\ \text { TCM } & =\text { Transport Class Model } \\ V_{F S} & =\text { Final Segment of a Departure Airspeed with One Engine Inoperative } \\ V_{F T O} & =\text { Liftoff Speed } \\ V_{L O F} & =\text { Minimum Control Airspeed - Clean Configuration (Flaps and Gear Retracted) } \\ V_{M C} & =\text { Minimum Control Airspeed - Landing Configuration (Full Flaps, Gear Extended) } \\ V_{M C L} & =\text { Rotation Airspeed } \\ V_{R} & =\text { Stall Airspeed - Clean Configuration (Flaps and Gear Retracted) } \\ V_{S} & =\text { Stall Airspeed - Landing Configuration (Full Flaps, Gear Extended) } \\ V_{S O} & =\text { Beference Stall Airspeed - Takeoff/Approach Configuration at 1/2 Flaps } \\ V_{S R} & =\text { Best Rate of Climb Airspeed } \\ V_{X} & =\text { Speed Above Which a Takeoff will Proceed with One Engine Inoperative } \\ V_{Y} & =\text { Safe Takeoff Speed with One Engine Inoperative } \\ V_{l} & =\text { Angle of Attack } \\ V_{2} & \end{array}$

\section{Introduction}

$\mathrm{T}$ HE National Aeronautics and Space Administration (NASA) has developed a number of non-proprietary aerospace-related simulations for use by the public. These include several independently-developed turbofan engine simulations ${ }^{1-5}$ and at least one airframe simulation. ${ }^{6}$ While the engine simulations are freestanding, the airframe simulation contains a simplified engine model. Of these simulations, the Transport Class Model (TCM $)^{6}$ airframe simulation and the Commercial Modular Aero-Propulsion System Simulation 40k (C-MAPSS40k) ${ }^{4,5}$ turbofan engine model are of particular interest for research in such areas as aviation safety and autonomous operation. The TCM represents a generic, mid-sized, single-aisle transport aircraft with two wing-mounted engines. C-MAPSS40k models a 40,000-lbf thrust class, high-bypass ratio turbofan engine with a representative commercial-type controller. These independently-developed simulations are deemed to be compatible based on their size. In fact, the baseline TCM utilizes first-order engine models derived from C-MAPSS40k, that have dynamics that vary as a function of altitude and fan speed. However, they are based on look-up tables, ${ }^{6}$ so all physical and thermodynamic information is lost. The input to the TCM's simplified engine models is throttle position, the outputs are fan speed and thrust.

Using these simulations to perform meaningful research on integrated flight and propulsion control, or on the impact on flight dynamics resulting from propulsion control modification, requires replacing the simplified engine models with full nonlinear C-MAPSS40k simulations. This enables modification of the propulsion control system and allows access to internal engine variables within the integrated simulation. In order to have confidence that the results are representative of what could be expected in a fielded application, the integrated TCM/C-MAPSS40k simulation must be validated. There are several aspects to this integration, testing, and validation process. First, the interface between the airframe and propulsion system must be defined (fuel flow, Mach number, altitude, ambient temperature and pressure, throttle position, thrust, etc.). This is relatively straightforward, considering that these variables are standard in simulations of sufficient complexity. The more complicated aspect, once the two systems are combined, is to ensure that they are working together as they should. Simulated flying, especially when performed in a flight simulator by an experienced pilot, gives confidence that the models are integrated properly and that the physics captured in them is correct. However, successful integration does not mean the individual models are truly compatible. The Federal Aviation Administration (FAA) specifies minimum performance requirements for the combined system, and mandates that an aircraft meet them in order to be certified. ${ }^{7}$ Therefore, for a simulation to be considered representative of a real aircraft, it should display similar behavior. Because these simulations were developed independently and then integrated, not unlike the actual hardware they represent, it is particularly important to validate their combined performance.

The remainder of the paper describes the model integration, the test procedure used to validate the integrated simulation, and the results and analysis. The conclusions will discuss whether the certification testing justifies the combined simulation's use for advanced propulsion control and integrated flight and propulsion control research. 

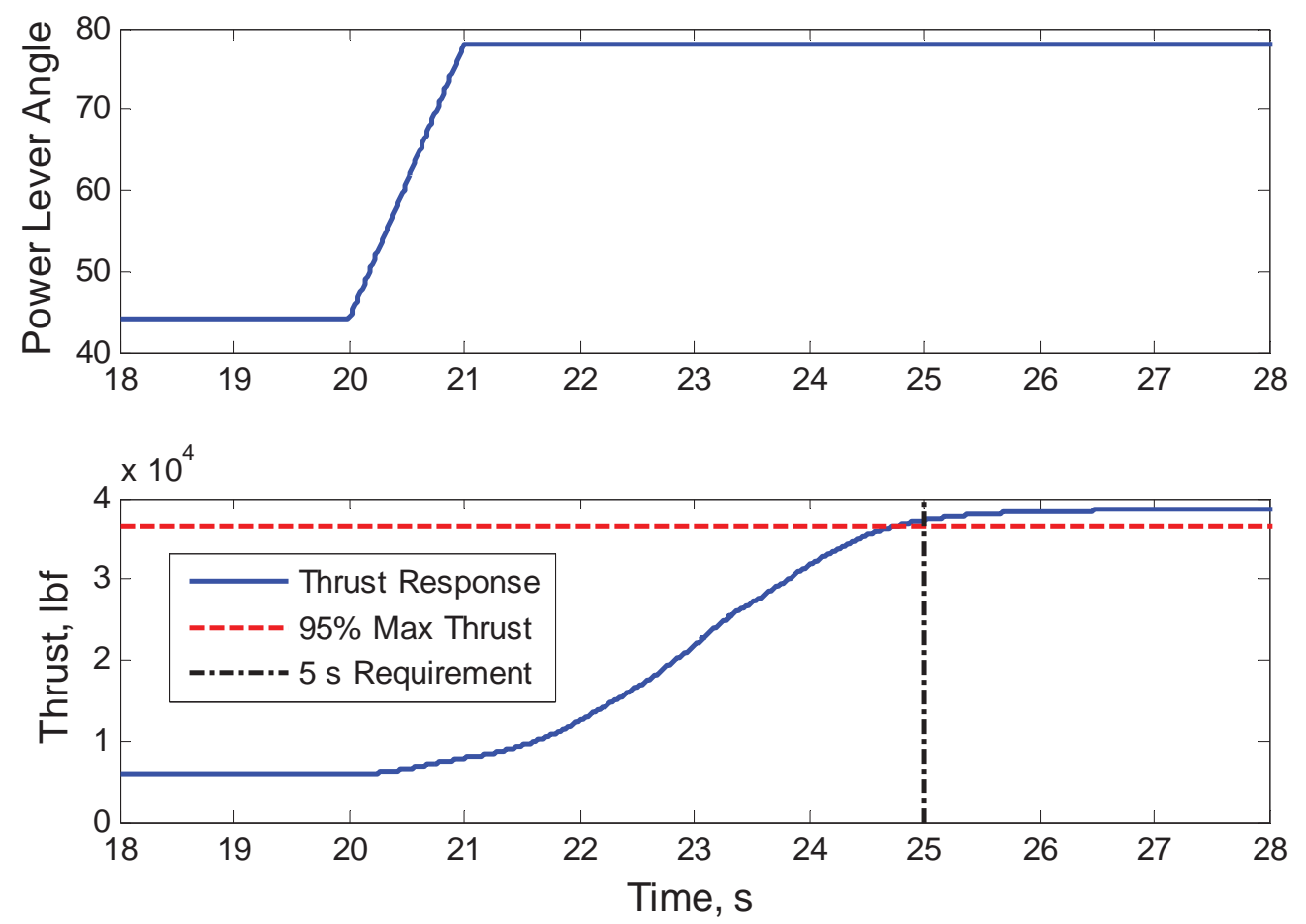

Figure 1. C-MAPSS40k response demonstrating compliance with §FAR 33.73(b) - Power or thrust response. Rise time from the fixed minimum flight idle power lever position to 95 percent of rated takeoff thrust is not over 5 seconds. Operating conditions are defined as sea-level static condition.

\section{Background}

For this work, the TCM, ${ }^{6}$ an airframe model with two wing-mounted engines, and two copies of the C-MAPSS40 ${ }^{4,5}$ turbofan engine model were integrated. The closed-loop C-MAPSS40k engine meets the relevant FAA thrust response criterion, FAR $\$ 33.73(\mathrm{~b})$, which requires that, from the fixed minimum flight idle power lever position, the thrust should reach 95 percent of rated takeoff power in not over 5 seconds (Figure 1) ${ }^{8}$ While important by itself, this is a stand-alone engine requirement. It is the resulting performance of the aircraft simulation with the engine models installed that will determine whether the integrated system is appropriate for use in meaningful piloted flight simulator testing. For example, an exemption may be granted for the engine response requirement (FAR $\$ 33.73(\mathrm{~b})$ ) on the basis of compliance with the climb performance for installed thrust requirement, FAR $\$ 25.119,{ }^{9}$ which states that the thrust achieved eight seconds after power application (starting from minimum flight idle) must allow a climb gradient (the ratio of the increase of altitude to horizontal distance travelled, expressed as a percentage) of not less than $3.2 \%$ for a go-around. ${ }^{10}$ Previous testing has demonstrated go-around maneuvers from a variety of approaches ${ }^{11}$ both stabilized and unstabilized. ${ }^{12}$ In all cases, the aircraft started to climb at a relatively constant rate within eight seconds (Figure 2), and much sooner in the more stabilized approaches (where the sink rate was less than $1000 \mathrm{ft} / \mathrm{s}$ at an appropriate approach speed). The actual requirement does not specify an initial speed or sink rate, meaning that starting the go-around from a stabilized approach, which is the best case, is acceptable. The integrated simulation should be suitable for non-real-time (i.e., faster than real time) desktop use, or for real-time piloted simulation. In either case, the integration and performance of the overall system is what is important. If the system is able to meet the FAA requirements for normal and emergency operation (e.g., one engine inoperative (OEI)), it will demonstrate that it is representative of a modern commercial aircraft. This will support the validity of the comparison of nominal and advanced control modes that could be evaluated using the simulation.

The specific certification requirements that will be evaluated are limited to those that are relevant to the types of research and flight regimes that the integrated model is used for, and more precisely, to the performance features captured in the model. This testing does not claim to be comprehensive. Actual certification of modern aircraft can take years, requiring over 1500 hours for the flight testing alone. ${ }^{13}$ Although this effort is, out of necessity, significantly scaled down, it will sample enough representative aspects of the requirements to justify confidence in the simulation. The regulations not tested include those related to: weather, including ice, rain, wind, and wind gusts; aerodynamic 


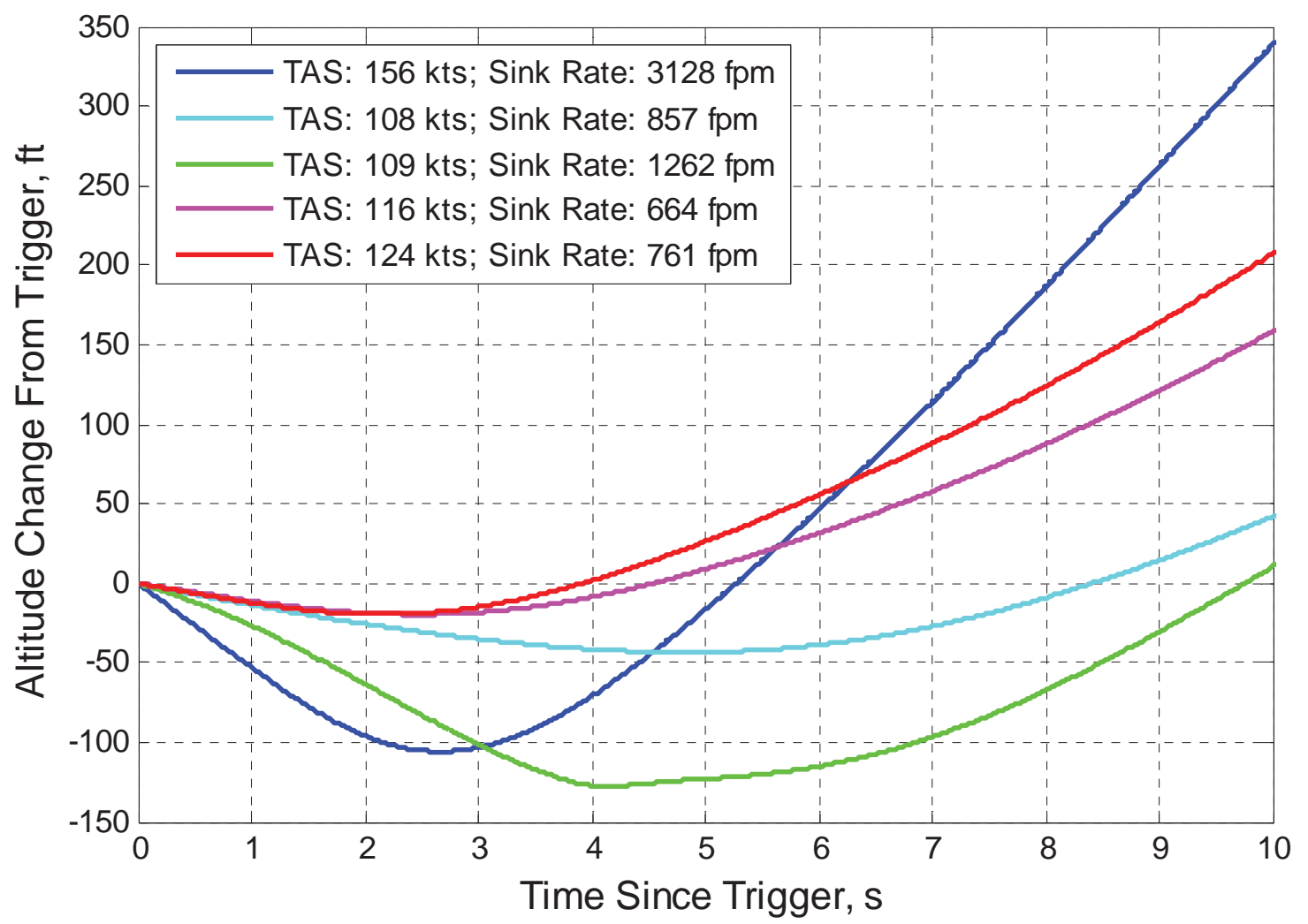

Figure 2. Altitude loss during a go-around for the integrated TCM/C-MAPSS40k simulation. The runs comprise various initial airspeeds and glide path angles; in all cases the throttle is at or near idle. True Air Speed, TAS, in knots, and sink rate, in feet per minute, at initiation are given for each case. At the longest, the minimum altitude occurred about five seconds after the maneuver was triggered, and in all cases, a relatively constant or increasing positive climb gradient was achieved in under eight seconds.

effects such as buffeting; fire hazards; passenger or cargo; aircraft to ground interaction during taxiing, takeoff and landing; changes in performance due to runway gradients; cockpit arrangement and instrumentation; control surface physics, including loads, range of motion, gust locks, or jamming; structural issues such as load factors; crosswind performance; and weight and balance (center of gravity).

\section{A. Integration of the simulations}

The two default engine modules within the TCM were each replaced by a copy of the closed-loop C-MAPSS40k engine model. The inputs to the engine models are pilot commands (e.g., throttle position) and flight conditions (e.g., altitude, Mach number). The engine models calculate net thrust, which is transferred back to the TCM and converted into body-axis force and moment components. Within the integrated simulation, application of thrust reversers on landing slows the aircraft by causing the thrust to change direction, i.e., point forward, at a level equal to $10 \%$ of the engines' net thrust; this ad hoc reduction loosely approximates the cancellation of forces since core thrust is not reversed, and bypass thrust is not redirected a full $180^{\circ}$. Other outputs, such as spool speeds and exhaust gas temperature, are used for cockpit instrumentation display when the integrated model is implemented in a flight simulator.

Fuel usage is another potential input to the TCM from C-MAPSS40k. The TCM can model the flow of fuel to the engines, where it is consumed, thus reducing the aircraft weight, ${ }^{6}$ but the amount of fuel used is determined by the engines. Since, in this implementation, the existing simplified engine models, which were replaced by copies of C-MAPSS40k, did not account for fuel at all, no attempt was made to make this connection in the integration, i.e., fuel flow is all internal to the engine models. This design choice is justified by the fact that the integrated simulation is planned to be used for short tests, lasting several minutes at most, where changes in overall aircraft weight would be negligible. Although the connection itself could be made with little effort, the accompanying changes in weight and inertias (of which only the baseline value of each is provided with the TCM simulation), and the resulting 


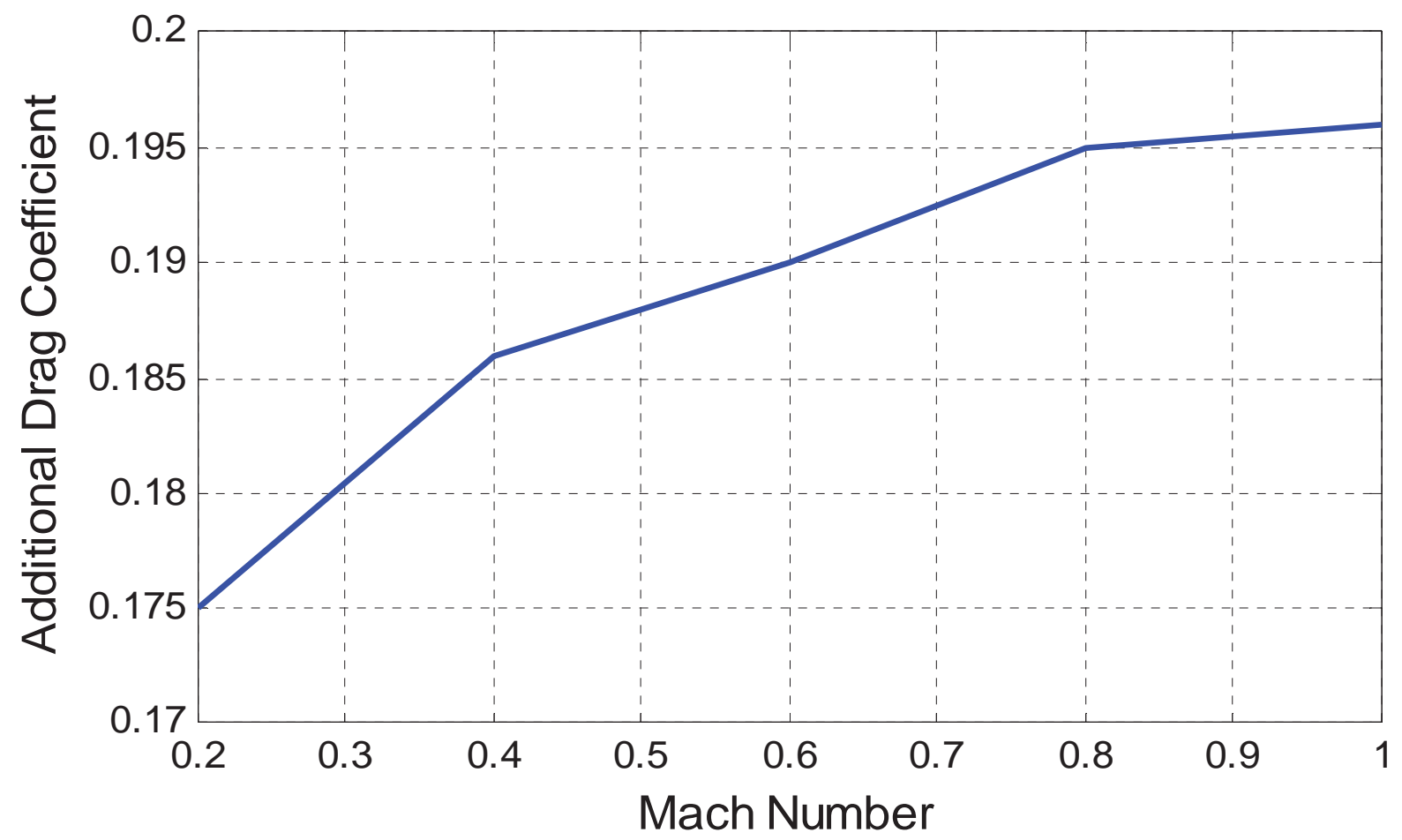

Figure 3. Additional engine drag coefficient due to windmilling.

modification of the flight dynamics, would have to be incorporated. This modification and subsequent validation would be beyond the scope of this effort. However, it should be noted that the TCM is stated to represent a mid-value weight for a mid-sized transport aircraft $(185,000 \mathrm{lbs}) .{ }^{6}$ So, although the certification requirements for an aircraft are meant to cover its entire weight range, as long as all of the certification testing and research efforts are performed at a consistent aircraft weight, the research results can be deemed valid.

\section{B. Modification to the models}

In addition to the integration, two main modifications were made to the TCM: the landing gear model was modified and an engine out/windmilling model was added.

\section{Landing gear}

The landing gear model modification was intended to improve the aircraft's interaction with the ground. It is not related to the certification testing that is being reported in this paper.

2. Windmilling

Validation testing of aircraft performance under specific engine out scenarios is required for certification. To account for the additional drag contribution due to an engine shutdown during flight, windmilling (or unpowered spinning) models were implemented in each of the two C-MAPSS40k engine simulations within the TCM. The windmilling models are based on empirical data from the literature. ${ }^{14}$ The models provide engine spool speeds and thrust/drag in the event of a shutdown. Windmilling drag was obtained as the sum of two values: a baseline drag coefficient due to the thrust capability of the engine, and an additional contribution represented as a function of Mach number.

Using data from Reference 14, the baseline windmilling drag coefficient for the C-MAPSS40k engine was estimated to be 0.31 . The additional drag due to Mach number is shown in Figure 3. Note that the data displayed in Figure 3 begin at Mach 0.2, which is about the takeoff speed of the TCM. Any engine out testing below this speed uses the minimum value from Figure 3. The drag force is then calculated as:

$$
D_{\text {Wind }}=C_{D \text {,wind }} \times q \times A
$$

where $D_{\text {Wind }}$ is the drag force due to windmilling; $C_{D \text {,wind }}$ is the drag coefficient due to windmilling, which equals the sum of the baseline value, 0.31, and the contribution due to windmilling from Figure 3; $q$ is the freestream dynamic 


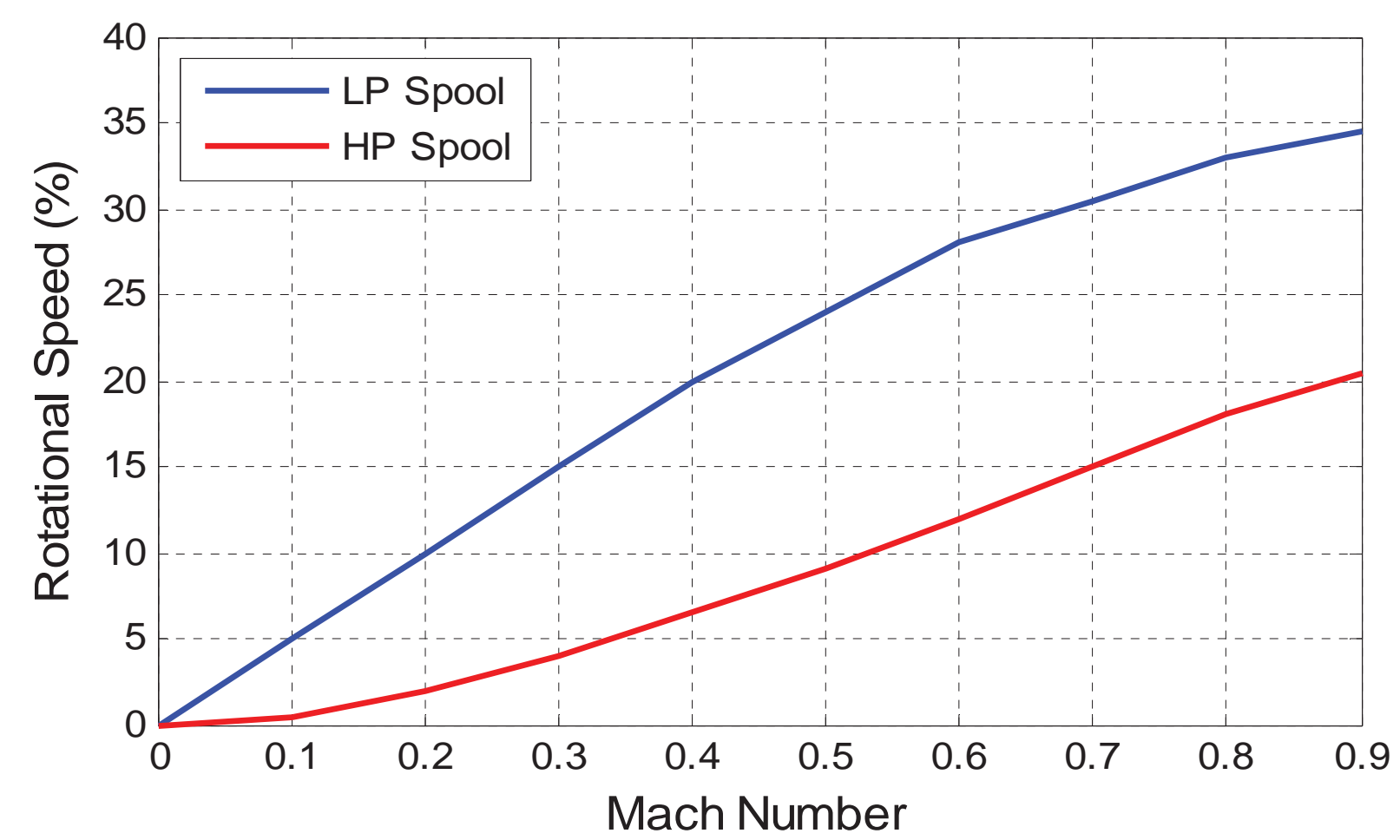

Figure 4. Modeled rotational speed of the engine spools due to windmilling.

pressure; and $A$ is the inlet area.

In the event of an engine failure, the TCM inputs switch from spool speeds and thrust values calculated by the C-MAPSS40k engine model to the speeds and drag values calculated by this windmilling model. When this switch occurs, a low-pass filter is applied to each parameter to simulate a more realistic, smooth transition between C-MAPSS40k and the windmilling model. Windmilling spool speeds are calculated as functions of flight Mach number (Figure 4). These parameters are used for flight simulator cockpit instrumentation displays and do not affect the physics of the aircraft model.

\section{Code of Federal Regulations Part 25}

The Federal Aviation Administration's Code of Federal Regulations (CFR) Part 25, "Airworthiness Standards: Transport Category Airplanes," is to be applied to aircraft in the category of the TCM. ${ }^{6}$ Although the standards apply to real aircraft, they are useful in gauging the realism of TCM performance. A systematic review was utilized to identify regulations that may be applied to the TCM. The process removed requirements that were not relevant to nor modeled within the TCM (e.g., loads, structure, wind, turbulence). The remaining regulations relate primarily to aspects of the TCM relevant to its use in research applications. That is not to say that performance-related features could not be incorporated in the future; wind and turbulence are worthy additions, and the effect of ice accretion, both on the structure and in the engines, is certainly a topic of interest. However, the scope of this work is limited to those regulations that specifically address the existing airframe and propulsion system model integration from a performance perspective.

The testing was further restricted to the regime in which the TCM is used. Flight test conditions were kept consistent when examining the TCM performance characteristics. Flight was executed at or below 5,000 feet MSL (mean sea level), the weight and balance of the aircraft model were kept constant, and a standard atmosphere was used. These test constraints go against the spirit of CFR Part 25, which seeks to confirm compliance across all operational weights, balances, altitudes and temperature variations. However, full compliance testing is beyond the scope of this paper, which has a goal of simply confirming the reasonableness of the TCM for research applications. 
Table 1. Common "V" speeds used with the TCM

\begin{tabular}{|l|c|l|}
\hline \multicolumn{2}{|c|}{ Speed (kts) } & Description \\
\hline$V_{F T O}$ & 127 & final takeoff airspeed \\
\hline$V_{M C}$ & 115 & minimum control airspeed - clean configuration \\
\hline$V_{M C L}$ & 90 & minimum control airspeed - landing configuration \\
\hline$V_{R}$ & 100 & rotation airspeed \\
\hline$V_{S}$ & 130 & stall airspeed - clean configuration (flaps and gear retracted) \\
\hline$V_{S O}$ & 96 & stall airspeed - landing configuration (full flaps, gear extended) \\
\hline$V_{S R}$ & 110 & reference stall airspeed - takeoff/approach configuration at $1 / 2$ flaps \\
\hline$V_{X}$ & 176 & best angle climb airspeed \\
\hline$V_{Y}$ & 358 & best rate of climb airspeed \\
\hline
\end{tabular}

The regulations were reduced and grouped into four performance areas: stalls, takeoff, climb, and stability. For each, there is an introduction and results section. However, before the simulated certification process began, analysis was performed to determine the common aircraft reference speeds, called "V" speeds. ${ }^{15}$ Table 1 lists these speeds for the TCM.

Values for the common "V" speeds given in Table 1 were determined analytically and empirically. The final takeoff speed, $V_{F T O}$, was determined experimentally in the flight simulator by noting when the TCM consistently lifted off from the runway at takeoff. The minimum control airspeeds, $V_{M C}$ and $V_{M C L}$, were determined experimentally in the flight simulator by the pilot flying maneuvers with one engine inoperative. The objective of this test was to determine the airspeed above which the rudder authority is sufficient to counteract the thrust asymmetry. The rotation airspeed, $V_{R}$, was determined by trial-and-error. The selected $V_{R}$ is somewhat subjective because the aircraft is able to rotate at a lower speed, but the value consistently gave good performance. The stall speeds, $V_{S}, V_{S O}$, and $V_{S R}$, were determined experimentally and analytically. Using the TCM aerodynamic database, the maximum lift coefficient, $C_{L, \max }$, was found; there is a different maximum lift coefficient for each flap setting. The stall speed is determined using the equation,

$$
V_{\text {stall }}=\sqrt{\frac{2 \times \text { weight }}{\text { density } \times S \times C_{L, \max }}}
$$

where the aircraft weight and air density are known constant values, and $S$ is the area of the wing, which is about 1950 $\mathrm{ft}^{2}$. The stall speeds calculated for each flap configuration at sea level were confirmed against experimental results from the flight simulator.

The best angle and rate of climb speeds were determined analytically. A velocity range was selected (i.e., 150 kts $-450 \mathrm{kts}$ ) and for each point in the velocity profile, the dynamic pressure, $q$, was calculated using

$$
q=\frac{1}{2} \times \text { density } \times \text { velocity }^{2}
$$

From the dynamic pressure, the required coefficient of lift, $C_{L}$, was determined for the given aircraft weight using

$$
C_{L}=\frac{w e i g h t}{q \times S}
$$

Using the aerodynamic database, the angle of attack, $\alpha$, for the given $C_{L}$ was determined. Then, given $\alpha$, the corresponding drag coefficient, $C_{D}$, was found from the aerodynamic database. Finally, the drag, $D$, was determined using 


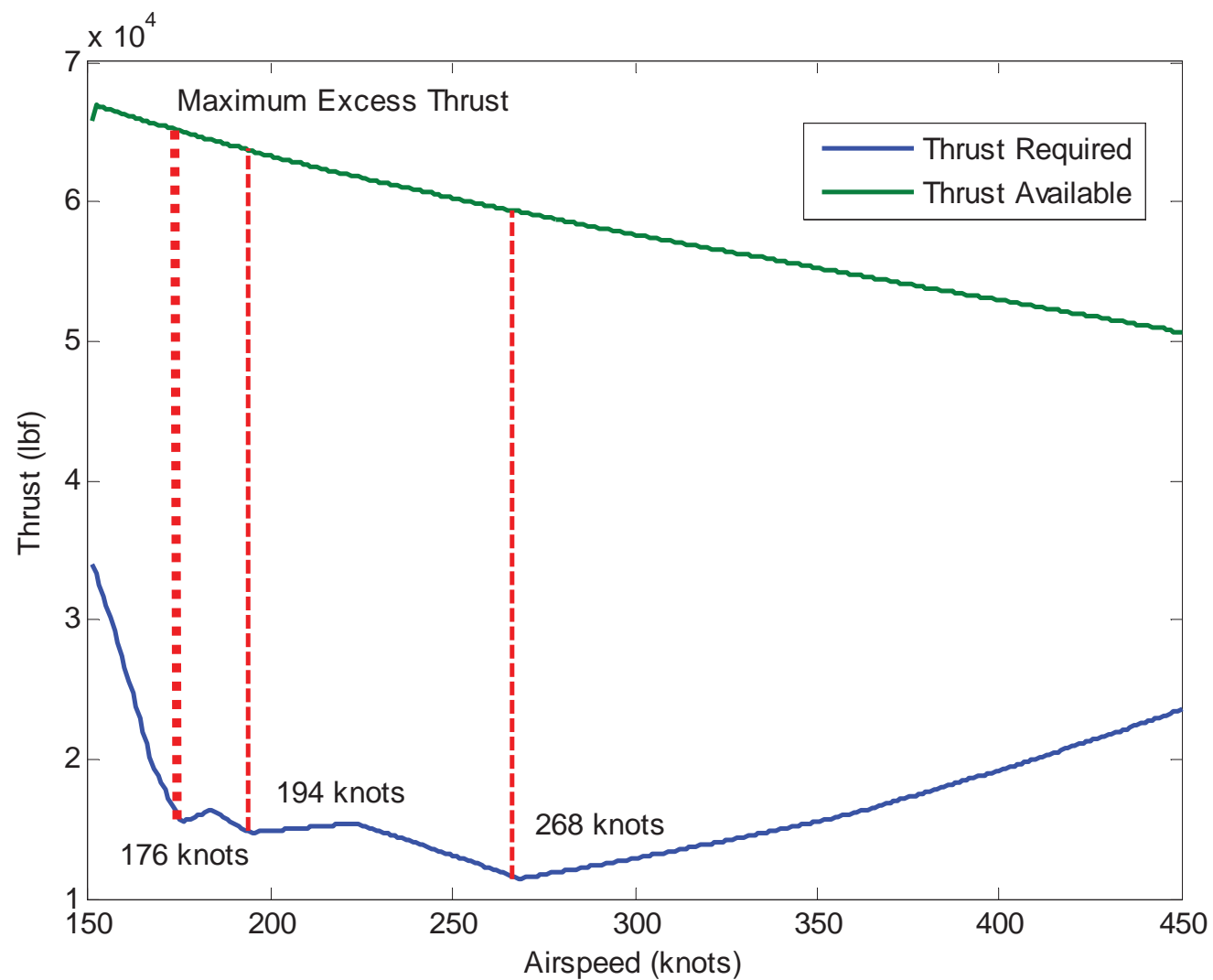

Figure 5. Maximum excess thrust airspeed at sea level (best angle of climb airspeed, $V_{X}$ )

$$
D=q \times S \times C_{D}
$$

The thrust required for steady flight at the given velocity is equal to the drag. Using this information, the thrust available from the two engines at full power and the thrust required for steady flight can be plotted versus velocity (Figure 5). The best angle of climb speed, $V_{X}$, is the airspeed with the greatest climb per horizontal distance; it is the airspeed with the maximum excess thrust, which was found to be 176 knots. Because of the variation in the thrust required curve, there are two secondary speeds (local maxima), 194 knots and 268 knots, which will maximize climb angle performance for higher airspeeds. These secondary angle of climb speeds are also indicated in Figure 5.

The best rate of climb speed, $V_{Y}$, is the airspeed that produces the fastest rate of climb (i.e., shortest time to climb) and is the airspeed with the maximum excess power. Power is determined using,

$$
\text { power }=\text { thrust } \times \text { velocity }
$$

From this equation, the power required and the power available from the two engines at full power are computed across the velocity profile and plotted in Figure 6. From these data, the maximum excess power airspeed $\left(V_{Y}\right)$ is found to be at 358 knots.

Knowing the maximum excess power allows for the maximum rate of climb to be calculated. To find the maximum sustainable rate of climb, the excess power is divided by the airplane weight as shown by

$$
\max R / C=\frac{\text { Power }_{\text {avail }}-\text { Power }_{\text {req }}}{\text { weight }}
$$

This gives a maximum rate of climb of $127 \mathrm{ft} / \mathrm{s}$ or $7,619 \mathrm{ft} / \mathrm{min}$. 


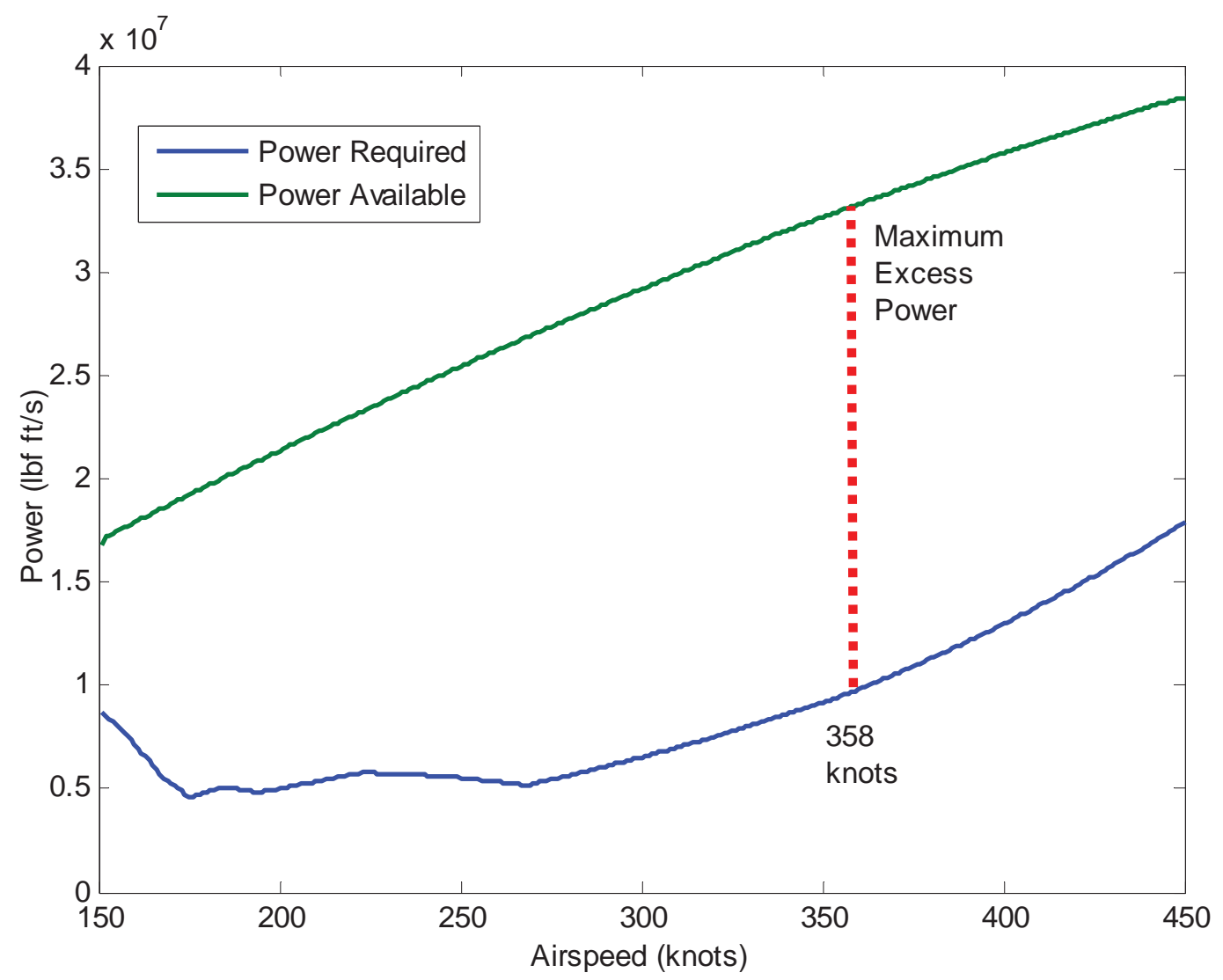

Figure 6. Maximum excess power airspeed (best rate of climb airspeed, $V_{Y}$ )

Ideally, the thrust required and power required curves should decrease to a minimum and then start increasing smoothly over the velocity range of interest. In Figure 5 and Figure 6, however, the slopes change sign several times from about 170 knots to about 265 knots. This variation is due to the $C_{D}$ profile in the TCM aerodynamic database. In the region specified by angle of attack $(\alpha)$ values from around $4^{\circ}$ to $10^{\circ}$, there are multiple increases and decreases in the slope of the $C_{D}$ versus $\alpha$ curve (Figure 7), ${ }^{6}$ that, when carried through the required thrust/power calculations,

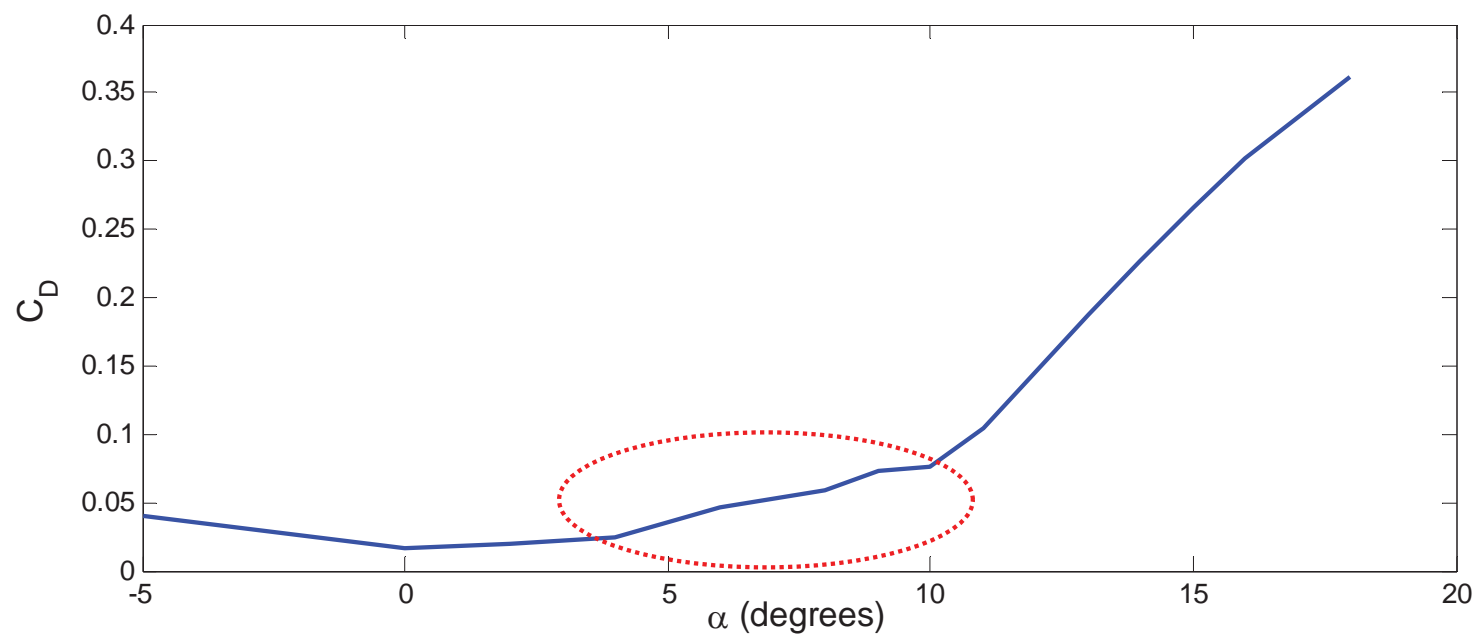

Figure 7. TCM coefficient of drag, $C_{D}$, versus angle of attack, $\alpha$, for no flaps (recreated from Reference 6). 
Table 2. Assumed airplane configuration during flight phases

\begin{tabular}{|l|l|l|}
\hline Flight Phase & Landing Gear & Flaps \\
\hline Takeoff & Retracted & Half Flaps \\
\hline Approach & Retracted & Half Flaps \\
\hline Landing & Extended & Full Flaps \\
\hline Cruise & Retracted & No Flaps \\
\hline
\end{tabular}

produce non-convex regions on the plots (Figure 5 and Figure 6). Because of this jaggedness, the climb performance of the TCM is not as sensitive to variations in airspeed as other aircraft with more definitive $V_{X}$ and $V_{Y}$ speeds. This is especially true for the best angle of climb speed, where local maxima produce two secondary angle of climb speeds.

Attempting to use the calculated climb performance speeds, particularly $V_{Y}$, would lead to operational challenges. On takeoff, it is difficult to accelerate to these speeds with a $V_{F T O}$ of 127 knots. To achieve a high performance takeoff climb, the airplane would be required to lift off, fly level to accelerate, and then climb when the desired airspeed is attained. The acceleration portion of this maneuver would impose a penalty in the climb gradient and would expose the airplane to risk in the event of an engine failure. Another consideration is that the $V_{Y}$ speed would not be permissible for an actual aircraft taking off at a sea level airport, dictated by CFR $\$ 91.117$ (a), which states that there is a 250 knot indicated airspeed limit while flying below 10,000 feet MSL.

In the evaluations presented in the following sections, four airplane configurations were standardized for consistency, as shown in Table 2. It is assumed that the takeoff and approach configurations for the TCM are the same. Figure 8 shows the flight segments used in this analysis, along with the various speeds, power settings, and aircraft configurations. Because of modeling limitations, takeoff examinations begin at $35 \mathrm{ft}$ above ground level (AGL), where it is assumed that the landing gear has been retracted, but the flaps are still deployed (Second and Third Segments). At the end of the initial takeoff climb, flaps are raised and the airplane is then in a cruise configuration as it continues its climb out to its desired altitude at a reduced power setting (Maximum Continuous Thrust or MCT) (Final Segment). The speeds shown in Figure 8 are defined in the nomenclature and important values for the testing described here are provided in Table 1.

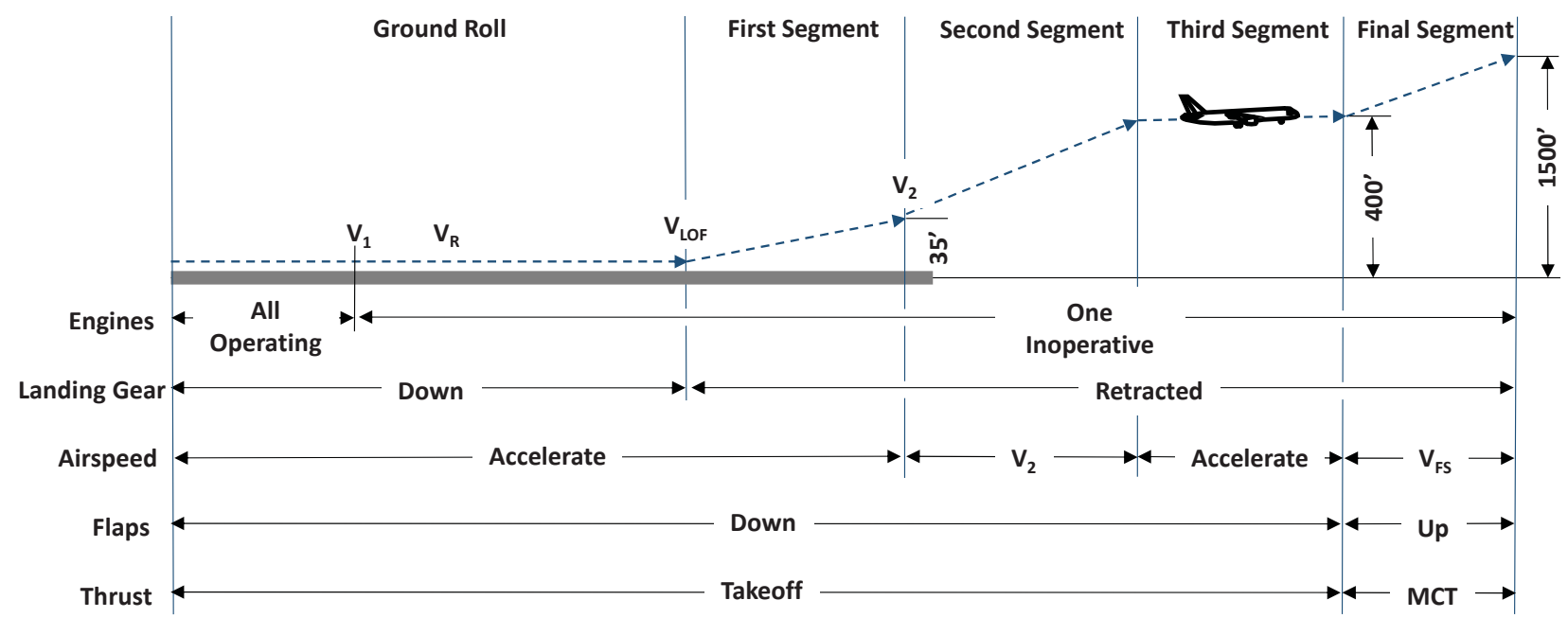

Figure 8. Flight path showing flight segments used in certification, along with the various speeds, power settings, and aircraft configurations. 


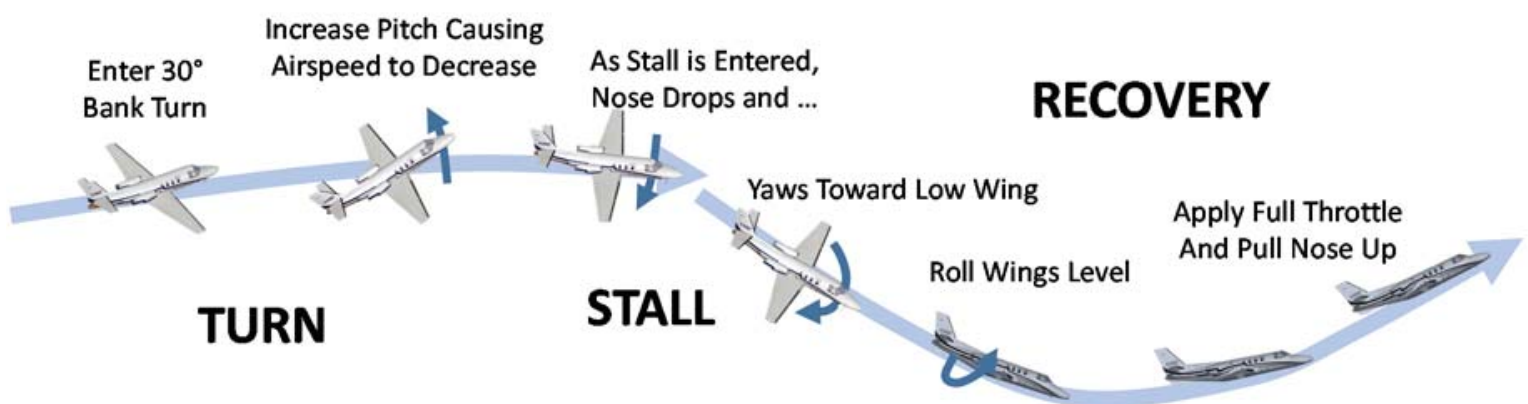

Figure 9. The procedure used to stall the aircraft in a turn.

\section{A. Stalls}

Stall occurs when the angle of attack is too great for the wing to produce lift. The airflow separates from the wing causing loss of lift. This typically occurs during approach due to slow airspeed, or during a takeoff climb that is too steep.

Due to its hazardous nature, airplane stall behavior is managed through several regulations in CFR 25: §25.103, $\S 25.201$ and $\$ 25.203$. These regulations stipulate that stalls are to be demonstrated from a stabilized trim condition in both straight flight and in a 30 degree banked turn. When encountered, the airplane is to give a clear and distinctive indication of the stall, and it is to react with no excessive banking or pitching so that an average pilot may regain control.

For level flight, the stall speeds were determined empirically. The procedure required the pilot to retard the throttles to idle and increase $\alpha$ in an attempt to maintain altitude as the airspeed decreased. Once the aircraft stalled, it began to descend and the nose dropped. The pilot applied full power and pulled up to recover. The reference stall speed $\left(V_{S R}\right)$ was selected in the takeoff/approach configuration with flaps set to one half. In this configuration, the airplane was found to stall at 110 knots. In the landing configuration, the airplane stalled at 96 knots $\left(V_{S O}\right)$. In a cruise configuration, the airplane stalled at 130 knots $\left(V_{S}\right)$. Stalls in level flight were stable with easy recovery.

The procedure to stall the aircraft in a turn is shown in Figure 9. The plane was put into a $30^{\circ}$ banked turn with half flaps, the throttles were retarded to idle, and the nose was slowly pulled up to increase $\alpha$ while maintaining altitude. When stall occurred, the nose dropped as the aircraft yawed toward the low wing. Altitude loss was gradual and, as shown in Figure 10, the aircraft began to accelerate slowly. The airplane was stable throughout the maneuver

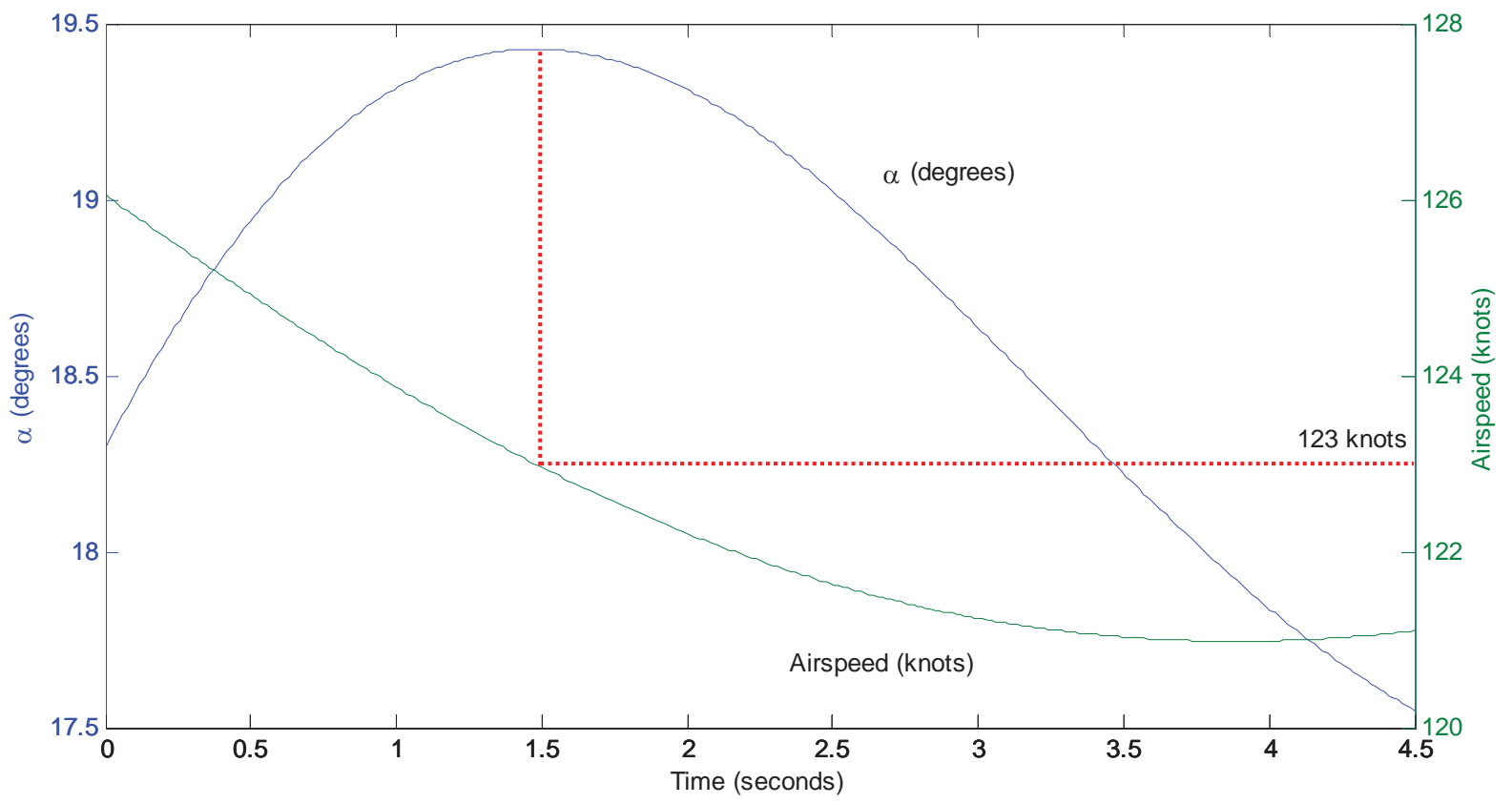

Figure 10. Stall during 30 degree banked turn. Airspeed and angle of attack, $\alpha$, are shown vs. time. 

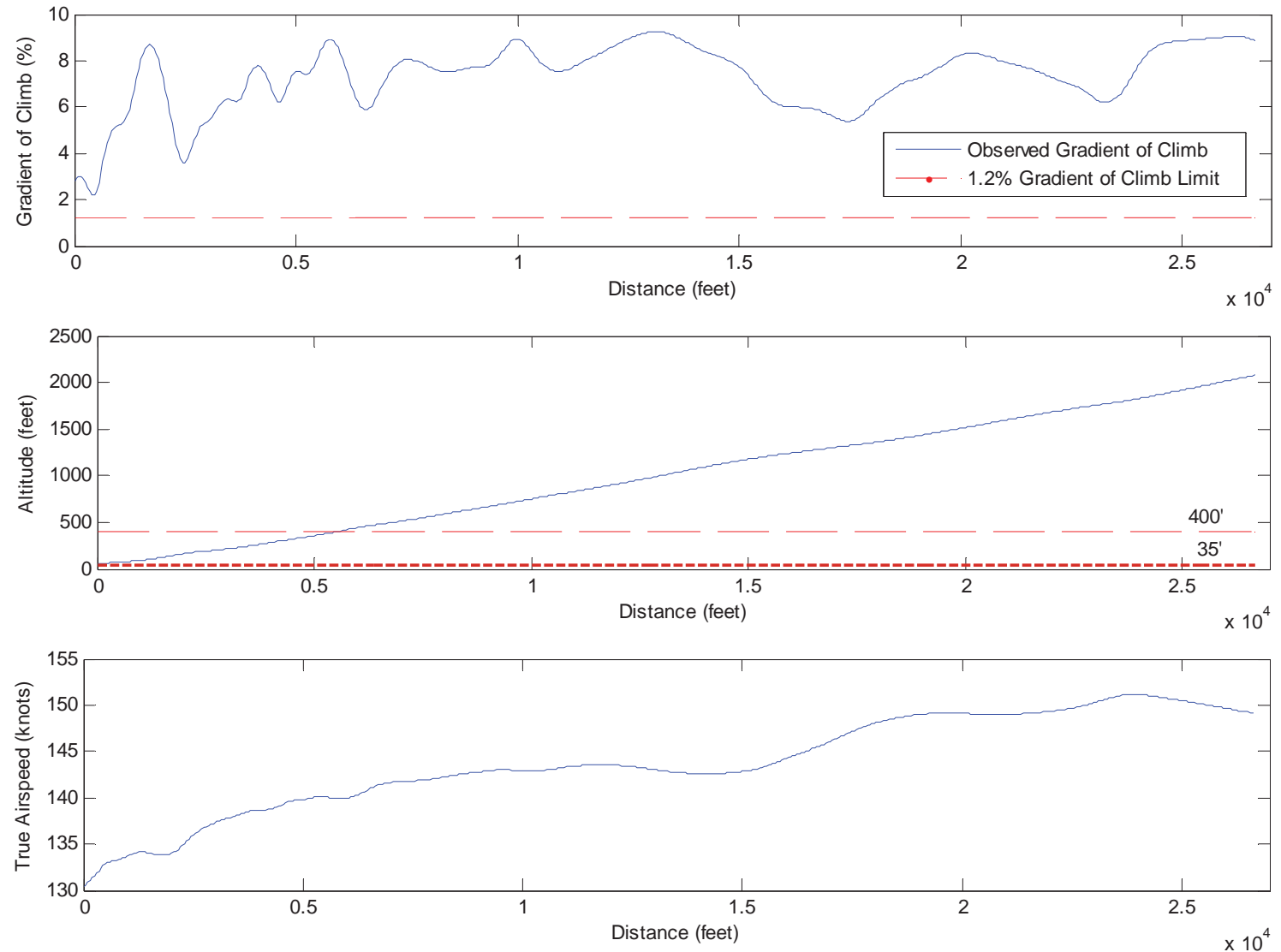

Figure 11. Gradient, altitude, and true airspeed during takeoff with one engine inoperative.

with little change in bank angle being noted. Recovery was achieved by rolling wings level, applying power, and pulling up. It was prompt and easily executed. Stall speed was approximately 123 knots, at which point $\alpha$ started to decrease, as indicated in Figure 10.

\section{B. Takeoff}

TCM takeoff performance was evaluated against portions of CFR \$25.111. Because of modeling limitations, takeoff evaluations did not involve requirements on runway distance or the immediate runway environment. Therefore, the flight simulator studies began when the airplane was 35 feet above the runway to align with CFR regulations for initial climb out altitude. Per regulations, one engine is made inoperative during takeoff and, at 35 feet above the runway, the airspeed is to be at or above $V_{2}$, the safe takeoff speed. As the airplane climbs, the slope of the climb gradient is to be positive at each point. Once the airplane climbs above $400 \mathrm{feet}$, the climb gradient is to be not less than $1.2 \%$. The only change in airplane configuration permitted during this segment is landing gear retraction.

In the takeoff evaluation, the left engine was failed during rotation with flaps set at one half, and landing gear was retracted once a positive rate of climb was achieved. From Figure 11, it can be seen that the slope of the takeoff path remained positive and was well above the $1.2 \%$ gradient of climb requirement throughout the profile. At 400 feet, the airspeed was approximately 140 knots, well above the assumed $V_{2}$ speed of 127 knots ( $V_{2}$ was assumed to be the same as $V_{F T O}$ for this work). 
Table 3. Climb performance evaluation scenarios (AEO=All Engines Operational; OEI=One Engine Out).

\begin{tabular}{|c|c|l|c|}
\hline $\begin{array}{c}\text { Test } \\
\text { Scenario }\end{array}$ & $\begin{array}{c}\text { Engine } \\
\text { Status }\end{array}$ & \multicolumn{1}{|c|}{ Airplane Configuration } & Gradient of Climb Required \\
\hline 1 & AEO & Landing $-1 / 2$ flaps with landing gear extended & $3.2 \%$ \\
\hline 2 & OEI & Takeoff $-1 / 2$ flaps with gear extended & Positive \\
\hline 3 & OEI & Takeoff $-1 / 2$ flaps with landing gear retracted & $2.4 \%$ \\
\hline 4 & OEI & Final takeoff - flaps up with landing gear retracted & $1.2 \%$ \\
\hline 5 & OEI & Approach $-1 / 2$ flaps with landing gear retracted & $2.1 \%$ \\
\hline
\end{tabular}

\section{Climb}

The TCM was assessed for its ability to climb with all engines operating and one engine inoperative, as stipulated in CFR \$25.119 and §25.121. Evaluation considered the five test scenarios listed in Table 3, with gradient of climb being the primary measure of interest. In Test Scenario 1, the takeoff performance is measured with all engines operating, half flaps and the landing gear extended. This is the only climb evaluation scenario where engine response time comes into play. Per regulation, the aircraft is to have achieved, for go-around from minimum flight idle, a minimum climb gradient of $3.2 \%$ within eight seconds of power application to the go-around thrust setting. This is also the only climb evaluation with all engines operating, as the remaining test scenarios specify that one engine is inoperative. Test Scenarios 2 and 3 have flaps deployed and the landing gear extended and retracted, respectively. Test Scenario 4 specifies that the flaps and landing gear are retracted in a cruise configuration, while Test Scenario 5 has the same configuration as Test Scenario 3 but with a reduced gradient of climb requirement.

The five test scenarios were flown with the TCM travelling at airspeeds of around 130-145 knots. These speeds were used because they give good performance and are readily achievable during the takeoff climb out. They are also in the neighborhood of the speeds called for in the regulations, although in some cases are several knots higher than specified.

For Test Scenario 1, an approach to landing was flown with a go-around being executed at $50 \mathrm{ft}$ AGL. The resulting gradient of climb is shown in Figure 12. In this situation, the TCM had no difficulty in satisfying the $3.2 \%$ climb gradient requirement. In fact, by eight seconds after power was applied, the gradient requirement was greatly exceeded with values in the mid-20\% range.

In Test Scenario 2, a takeoff was flown with the TCM configured with half flaps and landing gear extended; one engine was inoperative. From the gradient of climb plot shown in Figure 13, it can be seen that the TCM met the positive gradient of climb requirement.

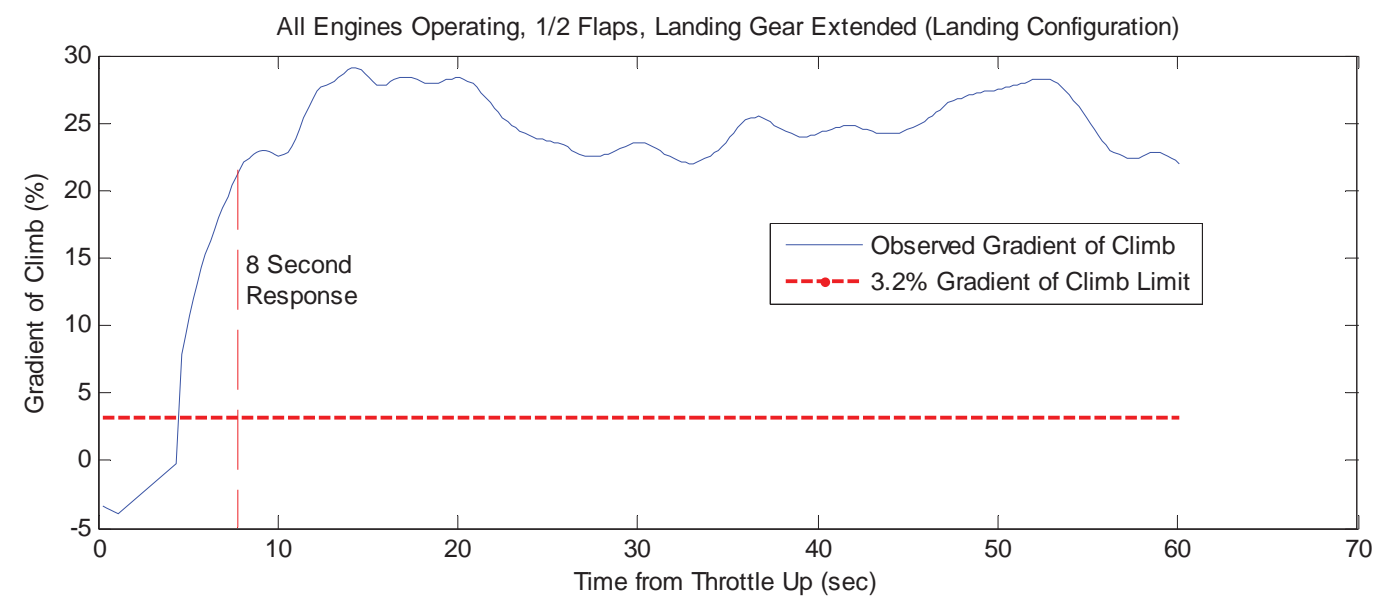

Figure 12. Gradient of climb for all engines operating in landing configuration (go-around) (Test Scenario 1). 


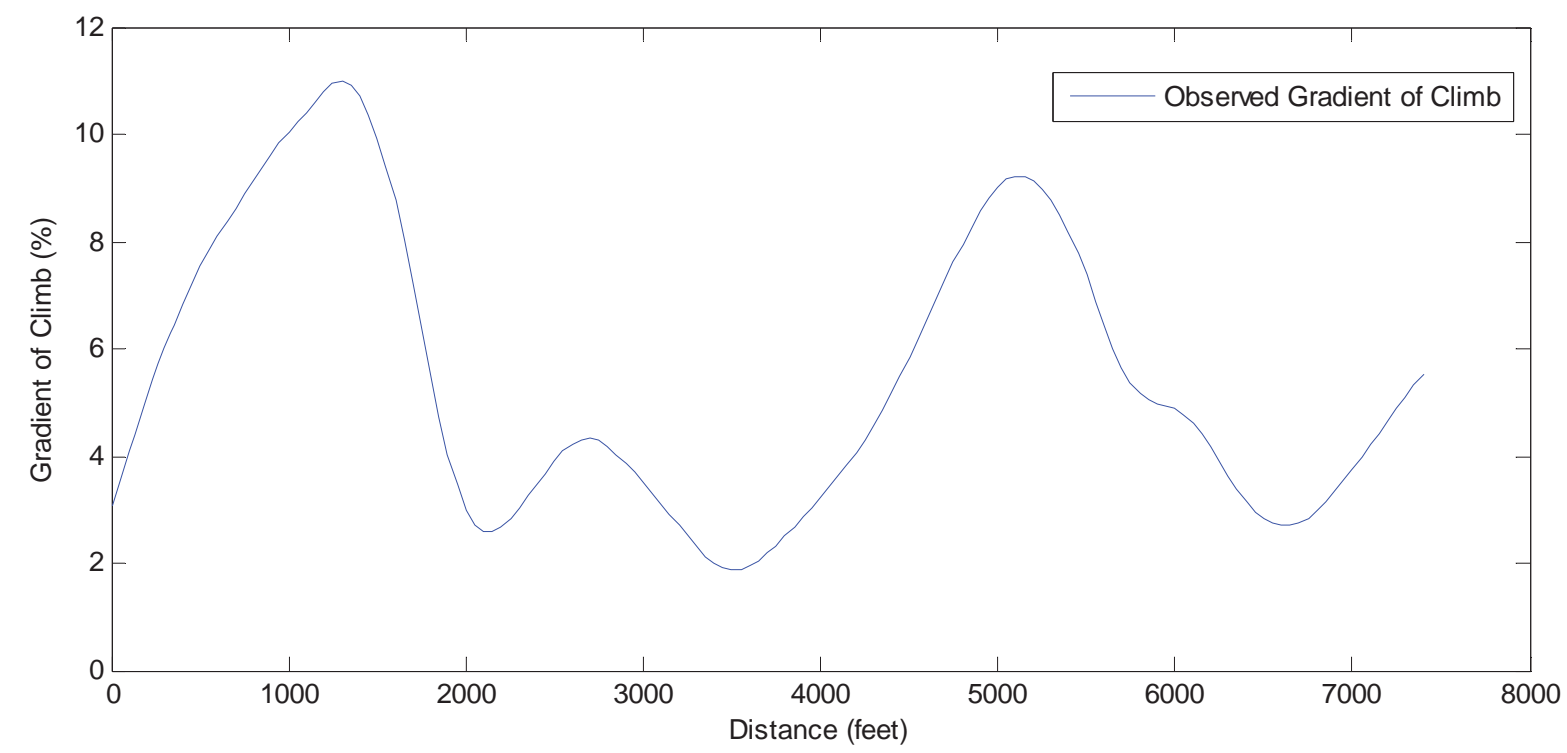

Figure 13. Gradient of climb for one engine inoperative in landing configuration (Test Scenario 2).

Test Scenarios 3 and 5 utilized the same TCM configurations. Test Scenario 3 is a takeoff climb while Test Scenario 5 is an approach go-around. In each of these cases, the TCM is in the same configuration with one engine inoperative. As shown in Figure 14, the TCM was easily able to satisfy the $2.4 \%$ (Scenario 3 ) and 2.1\% (Scenario 5) gradient of climb specifications.

In Test Scenario 4, climb performance at the end of the takeoff climb out is measured. The TCM has landing gear and flaps retracted in the cruise configuration with one engine inoperative. As shown in Figure 15, the TCM exceeded the $1.2 \%$ gradient of climb requirement.

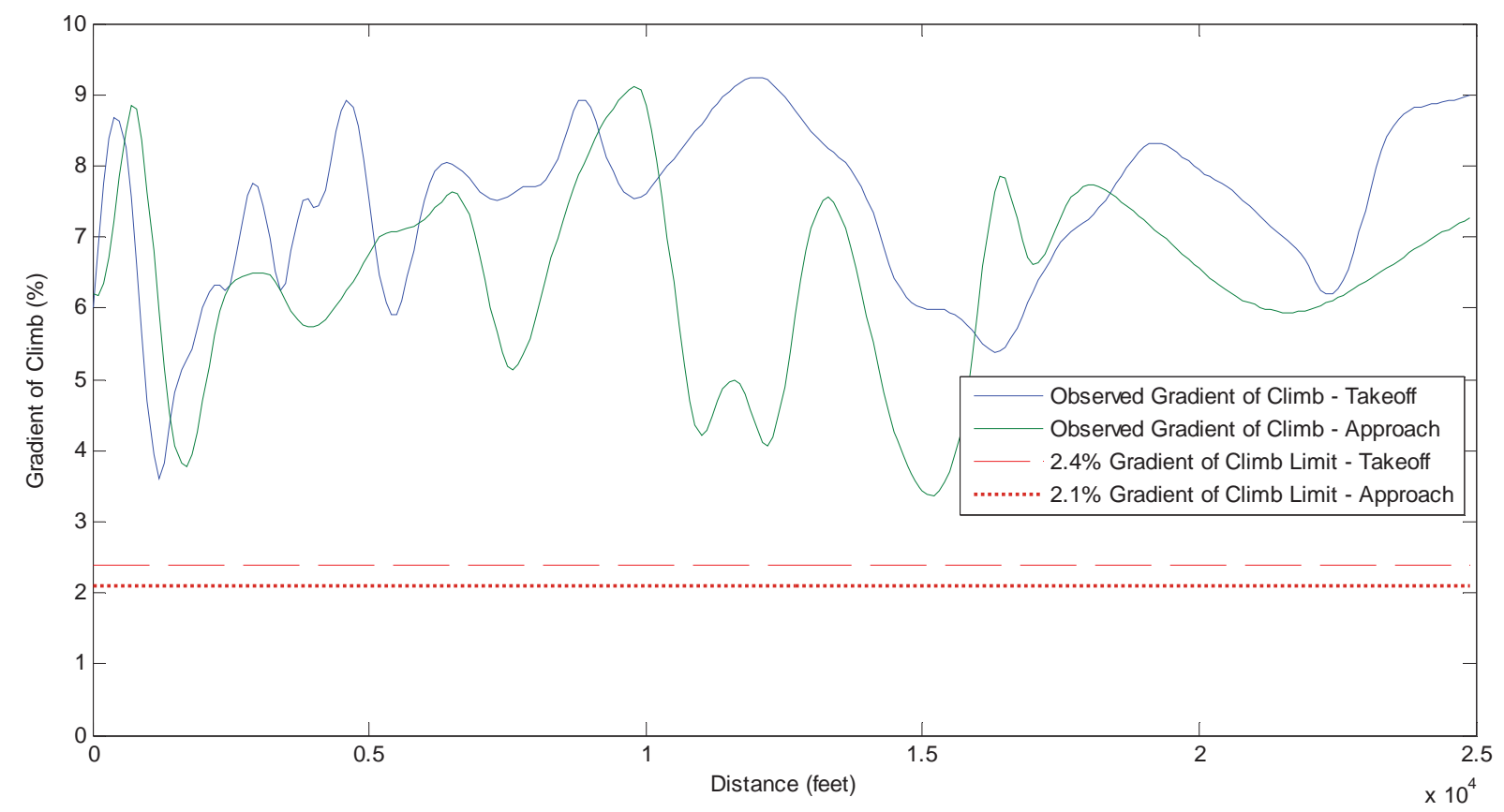

Figure 14. Gradient of climb for one engine operative in takeoff/approach configuration (Test Scenarios 3 and 5 , respectively). 


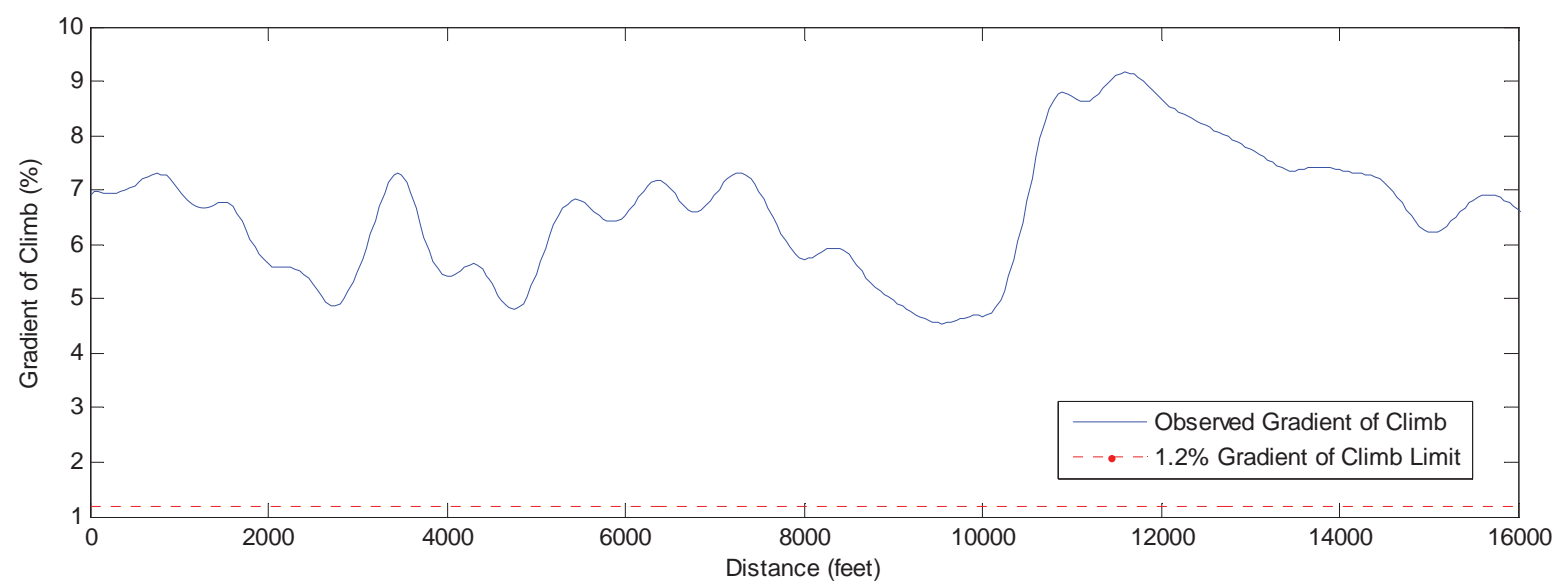

Figure 15. Gradient of climb for one engine operative in cruise (en route) configuration (Scenario 4).

\section{Stability}

The stability of the TCM was evaluated using the standards in CFR $\S 25.171, \S 25.173, \S 25.177$, and $\$ 25.181$. These regulations state that the airplane must be stable in all axes, longitudinally, directionally, and laterally, in any condition encountered during flight. Once trimmed for level flight, when a disturbance is experienced, the airplane must dampen any resulting oscillation and return to its trim condition. A pull on the control yoke or stick must be required to maintain speeds below the trim speed and a push to maintain speeds above.

To gauge the longitudinal stability, a perturbation is introduced to the flight controls to measure the TCM's ability to return to its trim condition. Per regulations, the airspeed is to return to within $10 \%$ of its value prior to the perturbation for the climb, approach and landing configurations, and to within $7.5 \%$ for the cruise configuration. Stability was tested by initiating a $10^{\circ}$ pitch up command followed by a release of the flight controls. The TCM was then allowed to settle back to its trim condition without any pilot input. The test was performed with the model in both the takeoff/approach and cruise configurations; the maneuver was initiated at airspeeds of 177 knots and 250 knots. From Figure 16, in the takeoff/approach configuration, the TCM appears to be dampening out the oscillations at both airspeeds. When the pilot input the $10^{\circ}$ pitch up command, the nose remained high. As the airspeed dropped off, the nose lowered and airspeed increased. As this repeated, the airplane began to settle back to its trim condition. When
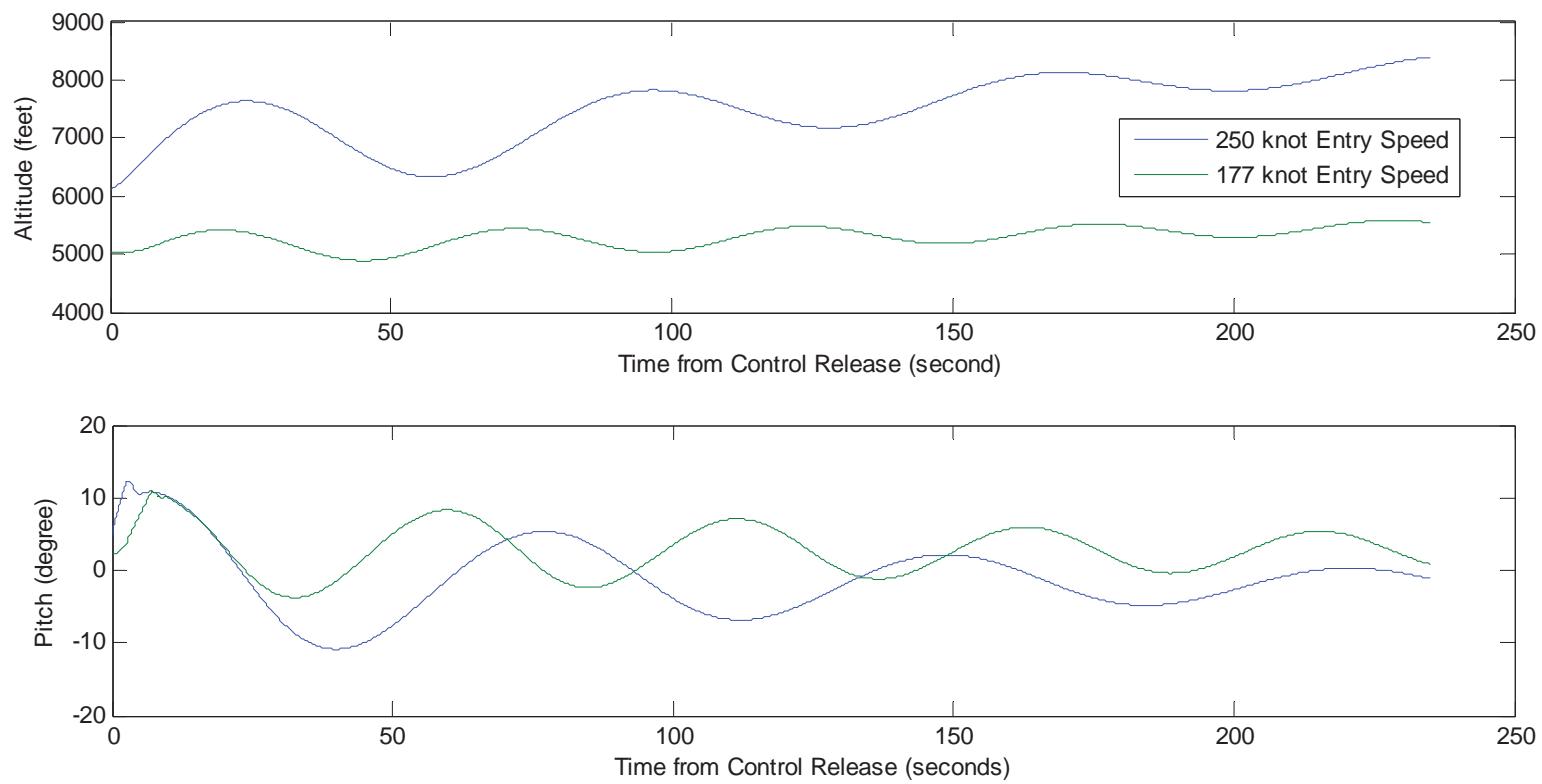

Figure 16. Response from flight control release after $10^{\circ}$ pitch-up (takeoff/approach configuration). 

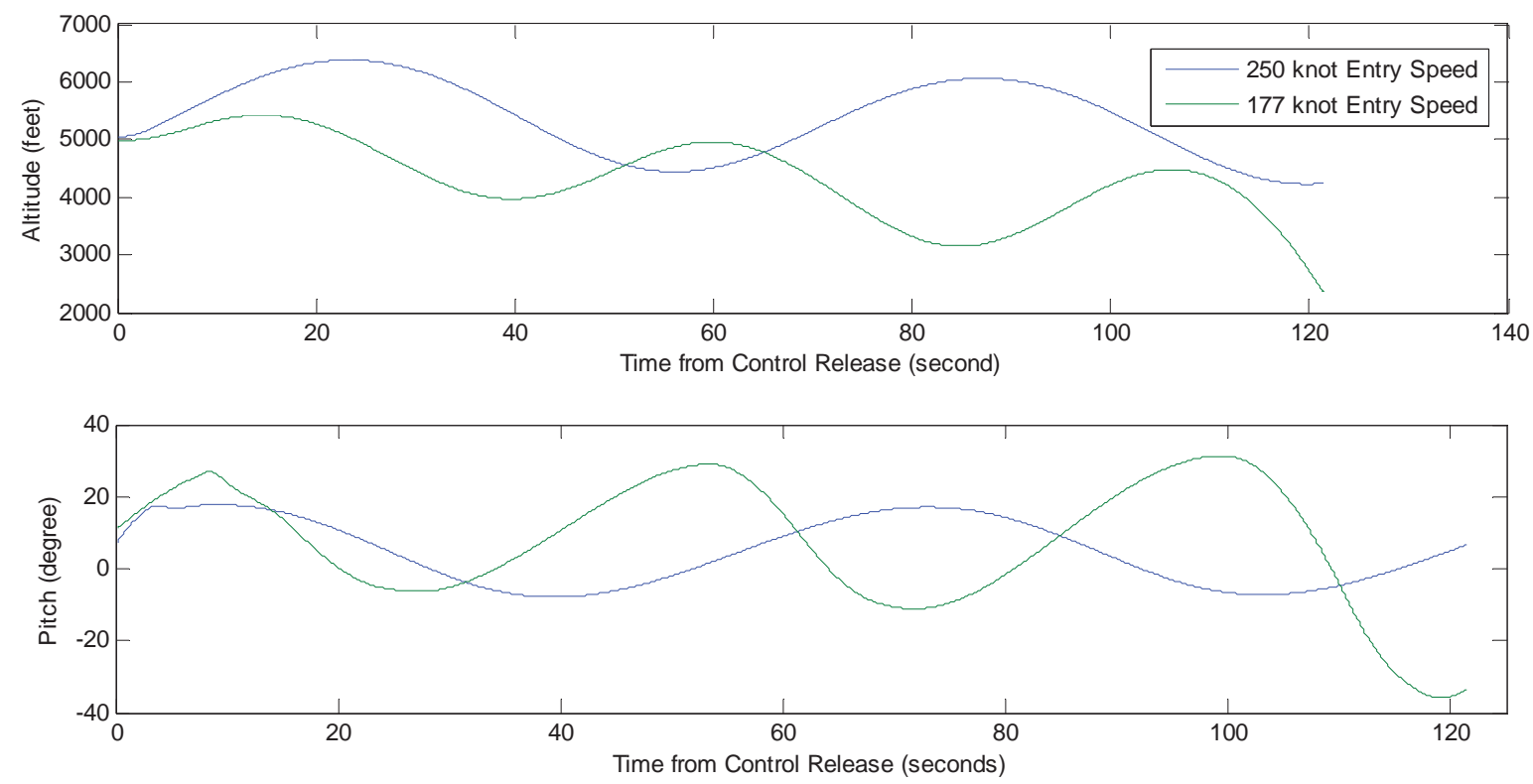

Figure 17. Response from flight control release after $10^{\circ}$ pitch-up (cruise configuration).

this was performed in the cruise configuration, shown in Figure 17, the nose remained high until the airspeed decreased. The airplane oscillated as it did in the previous scenario, but did not dampen out. In fact, for the case with the 177 knot entry speed, the airplane began to stall at the top of the climb, causing the nose to drop. Once it began to stall, the airplane became unstable, rolled to the left and nosed downward toward the ground. For the case with the 250 knot entry speed, the airplane appeared to be neutrally stable. The oscillations did not seem to increase nor decrease though altitude was lost with each pitch cycle.

For directional and lateral stability evaluation, the TCM, configured for cruise (no flaps, landing gear retracted), was placed in a skidding or uncoordinated turn and the flight controls were released. Per regulations, recovery from this condition requires the low wing in the turn to rise and the nose to return to the direction of flight. As with longitudinal stability, any combined lateral-directional oscillation must be dampened by the airplane whether the primary controls are free or fixed. When tested with the TCM, the nose turned back toward the direction of flight, but the low wing remained low. The airplane remained in the turn and oscillated in the lateral axis, as can be seen in Figure 18. The airplane had an undamped pitch oscillation that was becoming divergent. The TCM became unstable without intervention, although the pilot was able to regain control easily.

It is important to note that the version of the TCM used for this work did not include a feedback flight control system. Namely, yoke and pedal inputs were directly mapped to control surface deflections. A control and stability augmentation system, permissible under $\$ 25.672$, would be able to stabilize and dampen the oscillatory responses seen in Figure 16 through Figure 18.

\section{Discussion}

FAA-type certification testing was performed on the relevant aspects of the integrated TCM/C-MAPSS40k aircraft simulation, to evaluate its appropriateness as a research testbed. Overall the model performed well, exceeding most of the requirements easily. In fact, it generally appears to be a little overpowered, as evidenced by the ease with which it exceeded the takeoff and go-around climb requirements. On the other hand, the rudder seemed to very effectively compensate for the thrust imbalance incurred during the engine out tests. Together these observations seem to point to the aircraft being underweight for its size. In fact, it was previously stated that the weight is set to the middle of its empty to fully loaded range. Setting the weight to the upper limit of this range would certainly make it more challenging to meet the certification requirements, although whether it would still exceed the requirements is unknown. In order to perform the certification testing at the higher weight, the inertias would have to be modified 

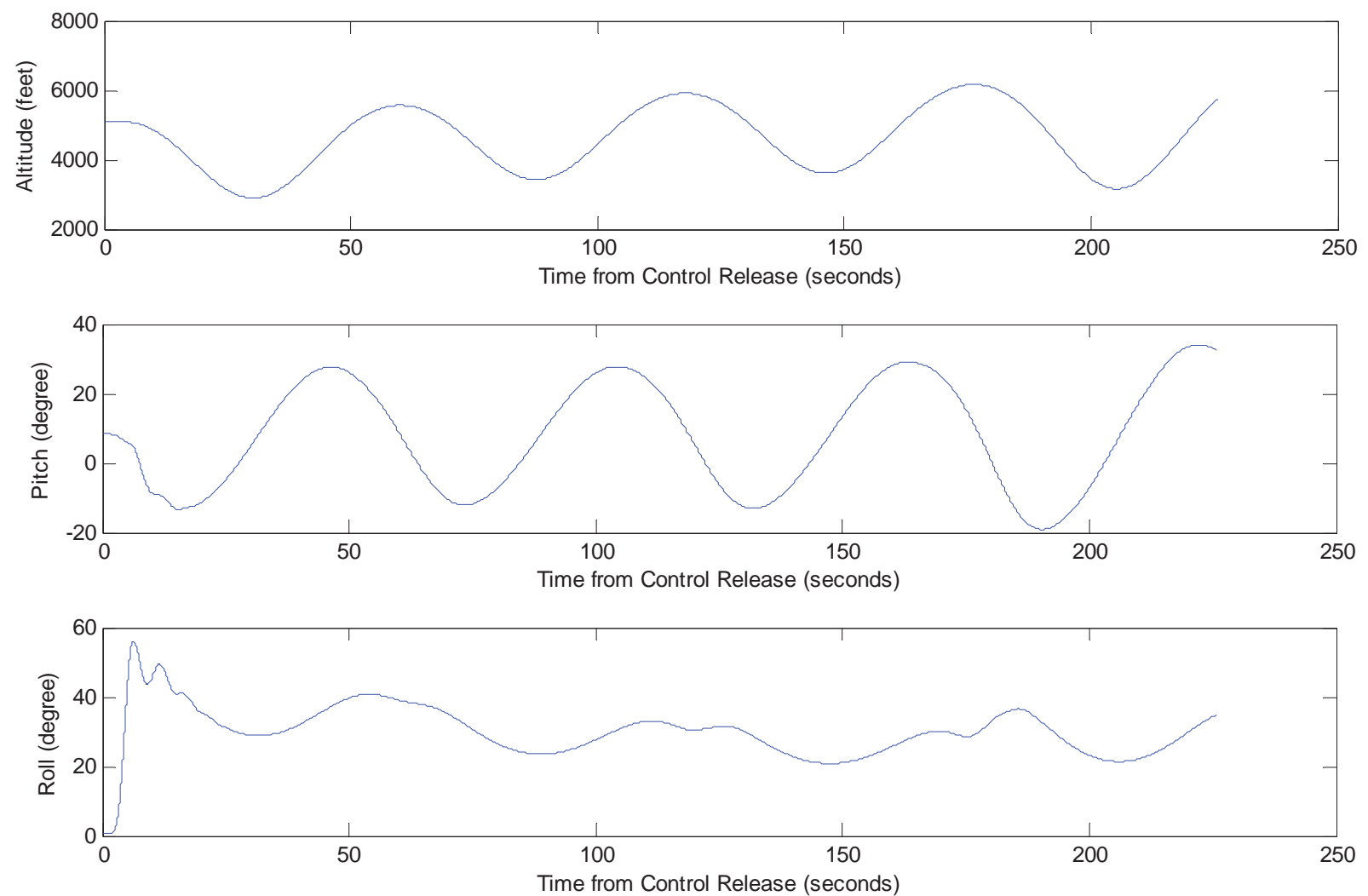

Figure 18. Response from flight control release during uncoordinated turn (cruise configuration).

correspondingly, and information regarding this is not provided with the TCM simulation. However, it is reasonable to assume that the excess power is due to the reduced aircraft weight rather than the engines being too large.

A somewhat more serious concern is the results of the stability testing. Undamped oscillations resulting from a pilot input under certain conditions might make the airframe fail the certification. However, the use of flaps counteracts this neutral stability, which, at least for research purposes, provides a workaround should testing in that regime be required. Additionally, these dynamics represent the inherent stability qualities of the airframe without a feedback control system. Given the slowly divergent nature of the responses observed, an appropriately designed control and stability augmentation system would improve the aircraft's stability characteristics. Furthermore, the pilot was able to easily maintain control despite these instabilities.

\section{Conclusions}

An integrated simulation consisting of the Transport Class Model (TCM) twin engine airframe simulation and two copies of the Commercial Modular Aero-Propulsion System Simulation 40k (C-MAPSS40k) turbofan engine simulation was evaluated against relevant aspects of the Federal Aviation Administration's Code of Federal Regulations (CFR) Part 25, "Airworthiness Standards: Transport Category Airplanes." The objective was to determine if the behavior of the combined model is representative enough of an actual aircraft to make it an appropriate testbed for advanced propulsion control and integrated flight and propulsion control research. Evaluation against the relevant certification criteria demonstrated that the integrated TCM/C-MAPSS40k simulation behaves like a lighter-than-fullweight commercial transport aircraft. Any potential problems exposed are relatively minor and can be ignored or worked around for research purposes. Therefore, the combined model is an appropriate testbed for use in such research.

\section{Acknowledgments}

The authors gratefully acknowledge the support of the NASA Aviation Safety Program, Vehicle System Safety Technologies Program for funding this work. 


\section{Reference}

${ }^{1}$ Parker, K. I. and Guo, T.-H., "Development of a Turbofan Engine Simulation in a Graphical Simulation Environment," NASA/TM-2003-212543, August 2003.

${ }^{2}$ Frederick, D. K., DeCastro, J. A., and Litt, J. S., User's Guide for the Commercial Modular Aero-Propulsion System Simulation (C-MAPSS), NASA/TM-2007-215026, October 2007.

${ }^{3}$ Liu, Y., Frederick, D. K., DeCastro, J. A., Litt, J. S., and Chan, W. W., User's Guide for the Commercial Modular Aero-Propulsion System Simulation (C-MAPSS), version 2, NASA/TM-2012-217432, March 2012.

${ }^{4}$ Csank, J., May, R. D., Litt, J. S., and Guo, T.-H., "Control Design for a Generic Commercial Aircraft Engine,” AIAA-2010-6629, 46th AIAA/ASME/SAE/ASEE Joint Propulsion Conference and Exhibit, Nashville, TN, July 25-28, 2010.

${ }^{5}$ May, R. D., Csank, J., Lavelle, T. M., Litt, J. S., and Guo, T.-H., "A High-Fidelity Simulation of a Generic Commercial Aircraft Engine and Controller," AIAA-2010-6630, 46th AIAA/ASME/SAE/ASEE Joint Propulsion Conference and Exhibit, Nashville, TN, July 25-28, 2010.

${ }^{6}$ Hueschen, R. M., "Development of the Transport Class Model (TCM) Aircraft Simulation From a Sub-Scale Generic Transport Model (GTM) Simulation,” NASA/TM-2011-217169, August 2011.

${ }^{7}$ Part 25 Airworthiness Standard: Transport Category Airplanes, Federal Aviation Administration. Electronic Code of Federal Regulations,

http://www.ecfr.gov/cgi-bin/text-idx?SID=0e4a2ad65997648baef3def32e3db379\&tpl=/ecfrbrowse/Title14/14cfr25_main_02.tpl, Last Accessed October 23, 2014.

${ }^{8}$ FAR $\$ 33.73(b)$ Power or Thrust Response

${ }^{9}$ FAR Part $§ 25.119$ : Landing climb: All-engines-operating.

${ }^{10}$ Civil Aviation Authority of New Zealand, Type Acceptance Report, TAR 11/21B/7, General Electric GE90-100 Series, Rev.0 : 21 October 2010.

${ }^{11}$ Litt, J. S., Liu, Y., Sowers, T. S., Owen, A. K., Guo, T.-H., "Piloted Simulation Evaluation of a Model-Predictive Automatic Recovery System to Prevent Vehicle Loss of Control on Approach," AIAA 2014-0036, AIAA Atmospheric Flight Mechanics Conference, National Harbor, MD, January 13-17, 2014.

12“Flying Stabilized Approaches," Operations Briefing Notes, Approach Techniques, Airbus Customer Services, Flight Operations Support and Services, 2005.

${ }^{13}$ Anon., "Boeing 787-9 Dreamliner Earns FAA, EASA Certification," http://boeing.mediaroom.com/2014-06-16-Boeing-787-9Dreamliner-Earns-FAA-EASA-Certification, Last Accessed November 3, 2014.

${ }^{14}$ Walsh, P.P. and Fletcher, P., "Gas Turbine Performance,” Second Edition, Blackwell Science, 2004.

${ }^{15}$ Anderson, J., Introduction to Flight, Second Edition, McGraw-Hill, New York, 1985. 